\section{Ikke treffende om osteoporose}

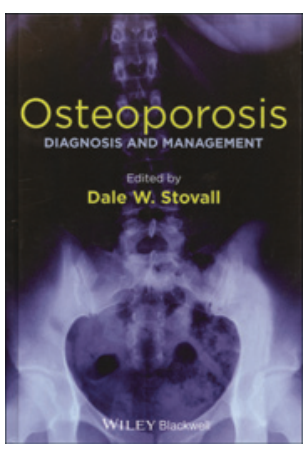

Dale W. Stovall, red.

\section{Osteoporosis}

Diagnosis and management. $278 \mathrm{~s}$, tab, ill. Chichester: Wiley-Blackwell, 2013.

Pris GBP 80

ISBN 978-1-119-96891-7

Redaktøren opplyser i forordet at målgruppen er leger i førstelinjetjenesten. Han har samlet er bredt panel av internasjonale eksperter, hvorav to norske, som har bidratt med hvert sitt kapittel. Inndelingen er tradisjonell, med 17 kapitler om epidemiologi, patofysiologi, diagnostikk og terapi ved osteoporose. Kapitlenes kvalitet og form varierer, men alle er informative, stort sett lettleste og bra oppdaterte. Referanselistene er generelt gode. Selv hadde jeg spesiell glede av kapitlene om beinremodellering, risikovurdering for beinbrudd, andre medikamenter enn glukokortikoider som årsak til osteoporose og om etterlevelsesproblemer i osteoporosebehandlingen. De ulike behandlingsalternativene for osteoporose omtales grundig, og man finner egne kapitler om glukokortikoidindusert osteoporose, osteoporose hos menn og om potensielle fremtidige behandlinger. Alle illustrasjoner er skjematiske og uten farger.

Jeg er usikker på om redaktøren treffer sitt publikum. I alle kapitlene formidles kunnskap som nok er mer myntet på spesialisten enn selv den engasjerte primærlege. Den noe knappe bruken av illustrasjoner og tabeller gir noen av kapitlene et heller monotont preg som påvirker både leselysten og oversikten. Når mer lettlest og komprimert informasjon kan hentes ned fra hjemmesidene til internasjonale og nasjonale osteoporoseforeninger og fra andre oversiktsartikler, vil nok primærleger heller benytte disse for å skaffe seg relevant og oppdatert informasjon om osteoporose. For spesialisten eller spesialister in spe er boken trolig for liten. For disse anbefales Primer of metabolic bone disease utgitt av American Society of Bone and Mineral Research.

Johan Halse

Praktiserende spesialist, Spesialistsenteret Pilestredet Park Oslo

\section{$\AA$ (over)leve med kløe}

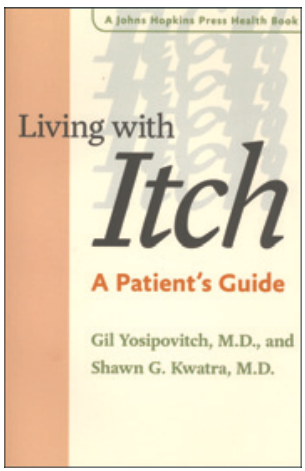

Gil Yosipovitch, Shawn G. Kwatra

Living with itch

A patient's guide. $129 \mathrm{~s}$, tab, ill. Baltimore, MD:

The Johns Hopkins University Press, 2013.

Pris USD 17

ISBN 978-1-4214-1233-7

Kløe kan være like plagsomt som smerte. Pasienters egne beskrivelser av å leve med en kronisk kløende hudsykdom får en sentral plass i denne boken. Interessant er det at pasienter, i tillegg til å ha en generelt nedsatt livskvalitet opplever kløe som skamfullt, barnslig og umodent, kanskje fordi å klore og klø seg på huden kan oppfattes som tegn på nedsatt selvkontroll.

Innledningsvis beskrives kløemediatorer, -reseptorer og kløetransmisjon fra sensoriske nerver i epidermis til sentralnervesystemet. I del 2 er mange ulike kløende hudsykdommer beskrevet med ledsagende pasienthistorier. Atopisk eksem, psoriasis, urticaria og hudlymfom får størst plass, mens f.eks. nevropatisk kløe og kløe assosiert med lever- og nyresykdom blir omtalt summarisk. Problemet med denne delen er at hver pasient - som vanligvis bare har én kløende sykdom - får relativt lite kunnskap om «sin» sykdom. Det vil sannsynligvis være raskere, billigere og bedre for pasienter å finne relevant informasjon på nettet.

Siste del er om behandling av kløe. Her er det gode praktiske råd. En del av håndkjøpspreparatene er ikke tilgjengelig eller har andre navn i Norge. En del ikke-godkjente eller eksperimentelle terapier omtales, f.eks. opioidet nalfurafine eller substans-P-agonisten aprepitant. Ved å inkludere slike preparater i behandlingsalgoritmen vil forfatterne kanskje vise at vi har dyp forståelse av kløemekanismer og at nye medisiner stadig utvikles. På den annen side, det er svært sjelden disse behandlingsmulighetene er aktuelle for leserne av denne boken.

I Norge har denne boken begrenset interesse. Den kan leses av pasienter som ønsker en oppdatert, pedagogisk og illustrert fremstilling av kløemekanismer og kløebehandling på engelsk. Pasienters egne beskrivelser er gode og kan også leses av fagpersoner. I Norge vil pasienter med atopisk eksem heller ha nytte av nettsiden www.eksemskolen.no.

Jon Anders Halvorsen

Overlege, Hudavdelingen

Oslo universitetssykehus, Rikshospitalet 